\title{
Feature Analysis on Auto Recalls Caused by Braking System Defects in China
}

\author{
Yongqin Feng ${ }^{1, a,{ }^{*}}$, Yan Yin ${ }^{2, b}$, Xiaorui Zhang ${ }^{3, c}$ and Lingyun Zeng ${ }^{4, d}$ \\ 1,2,3,4, Defective Product Administrative Center of AQSIQ, Beijing, 100191, China \\ afengyq@dpac.gov.cn, byiny@dpac.gov.cn, ${ }^{\mathrm{C}}$ zhangxr@dpac.gov.cn, ${ }^{\mathrm{d}}$ zengly@dpac.gov.cn
}

\begin{abstract}
Keywords: Auto recall; Braking System; Defect
Abstract. The features of auto recalls caused by braking system defects in China are analyzed on the basis of official authority statistical data on auto recalls in China. This study shows that the braking system defects attributable to hydraulic service brake secondary assembly take the highest proportion among auto recalls caused by braking system defects in China; main vehicles and main auto brands involved are passenger cars and joint-venture brands; the recall times involving domestic vehicles and imported vehicles is about the same, but the quantity of domestic vehicles involving recalls is 3.3 times that of imported vehicles. Though the recall times impacted by DPAC are small, a wider range of influence is produced.
\end{abstract}

\section{Introduction}

Auto braking system refers to one or more set(s) of devices arranged on vehicles, which the driver uses to control and produce an external force reverse to the vehicle running direction [1]. The function of braking system is to properly decelerate, stop or park the running vehicle as required by the driver and to keep a stable speed when the vehicle is running down the slope. Braking system is one of core auto parts and has a direct impact on the braking performance of vehicle. Good braking performance can ensure safe travelling of vehicles, reduce occurrence of traffic accidents, ensure safety of drivers, and improve safety of vehicles under extreme conditions.

The braking performance is an important indicator of safe travelling of vehicles, which the automobile management governmental departments of many countries pay special attention to. ECE R13 Appendix 6 of EC, ECE .71/320 Appendix III and US Braking Safety Standards FMV121 Clause S5.3.3 explicitly specify how to measure and limit the response time of braking system [2]. China issued a braking standard of GB12676-1999 Road Vehicle-Braking Systems-Structure, Performance and Test Methods in January 1999 and enforced it in October 1999. It is specified in Clause 5.4.2.1 that the time consumed from brake pedal acting to the pressure inside the most adverse brake chamber reaching $75 \%$ of its stable value cannot exceed $0.6 \mathrm{~s}$ if brake pedal is stepped within $0.2 \mathrm{~s}$.

However, since the auto braking system may have faults of insufficient braking force, unbalanced braking force and excessive retarding force of brake, thus causing overheating of brake drum, brake failure, etc., the automobile braking system fault in China is still one of main reasons for major traffic accidents of China and lots of auto recalls are produced each year due to braking system faults [3]. This paper expects to provide a reference for eliminating braking system defects, improving vehicle braking performance, continuously improving and perfecting the auto braking system through analyzing features of auto recalls caused by braking system defects in China in terms of recall times, quantity, recall type, secondary assembly, brand, vehicle type, etc.

\section{Data Source}

On October 1, 2004, the Provisions on the Administration of Recall of Defective Auto Products was officially implemented, which marks the establishment of a recall management system for defective auto products in China. On January 1, 2013, the Regulations on the Administration of Recall of Defective Auto Products was officially implemented, which opens a new stage of administration of defective auto products in China. According to management regulations, Auto product recalls in 
China receive supervision and management of the Administration of Quality Supervision, Inspection and Quarantine (AQSIQ); as a professional recall management technology support institution, the Defective Product Administration Center (DPAC) affiliated to AQSIQ is responsible for investigation of auto product defects, recall management, technical guarantee, study on key recalled technologies and education of consumers [4].

Tab.1 Recall Times and Quantity of Vechiles Caused by Braking System Defects

\begin{tabular}{ccccc}
\hline Year & Recall Times & $\begin{array}{c}\text { Percentage of } \\
\text { Total Times }\end{array}$ & Recalled Quantity & $\begin{array}{c}\text { Percentage of } \\
\text { Total Vehicles }\end{array}$ \\
\hline 2004 & 3 & $2.88 \%$ & 47585 & $2.29 \%$ \\
2005 & 5 & $4.81 \%$ & 14475 & $0.70 \%$ \\
2006 & 1 & $0.96 \%$ & 1231 & $0.06 \%$ \\
2007 & 4 & $3.85 \%$ & 31898 & $1.53 \%$ \\
2008 & 6 & $5.77 \%$ & 11409 & $0.55 \%$ \\
2009 & 6 & $5.77 \%$ & 276385 & $13.29 \%$ \\
2010 & 14 & $13.46 \%$ & 260222 & $12.51 \%$ \\
2011 & 3 & $2.88 \%$ & 9449 & $0.45 \%$ \\
2012 & 9 & $8.65 \%$ & 148235 & $7.13 \%$ \\
2013 & 26 & $25.00 \%$ & 839699 & $40.38 \%$ \\
2014 & 13 & $12.50 \%$ & 327344 & $15.74 \%$ \\
2015 & 14 & $13.46 \%$ & 111363 & $5.36 \%$ \\
Total & 104 & $100 \%$ & 2079295 & $100 \%$ \\
\hline
\end{tabular}

Since the founding, the DPAC will summarize relevant data about auto recalls each year to provide valuable data sources to study features of auto recalls caused by braking system defects. In order to ensure the reliability and validity of this study, this paper obtains all auto recall data from the DPAC with the time span from 2004 to 2015, and total 104 auto recalls and 2,079,295 vehicles are involved. As shown in Table 1, the statistics of auto recall times and percentage caused by braking system defects in China during 2004-2015 show that, the largest quantity of auto recalls and recalled vehicles caused by braking system defects appeared in 2013 , i.e. 26 auto recalls, taking $25.00 \%$ of total recall times; 839,699 vehicles are recalled, taking $40.38 \%$ of total recalled vehicles.

\section{Feature Analysis}

Recall Type. As shown in Table 2, there are 17 auto recalls initiated by DPAC survey among 104 auto recalls caused by braking system defects, occupying $16.35 \%$ of total recall times; 794,908 vehicles are involved, taking $38.23 \%$ of total recaclled vehicles. 
Tab. 2 DPAC Survey Influences on Auto Recalls Caused by Braking System Defects

\begin{tabular}{cccccc}
\hline $\begin{array}{c}\text { Whether Receive a } \\
\text { Survey by DPAC }\end{array}$ & $\begin{array}{c}\text { Recall } \\
\text { Times }\end{array}$ & $\begin{array}{c}\text { Percentage of } \\
\text { Total Times }\end{array}$ & $\begin{array}{c}\text { Recalled } \\
\text { Quantity }\end{array}$ & $\begin{array}{c}\text { Percentage of } \\
\text { Total Vehicles }\end{array}$ & $\begin{array}{c}\text { Average Quantity } \\
\text { (vehicles) of Each } \\
\text { Recall }\end{array}$ \\
\hline Yes & 17 & $16.35 \%$ & 794908 & $38.23 \%$ & 46759 \\
No & 87 & $83.65 \%$ & 1284387 & $61.77 \%$ & 14763 \\
Total & 104 & $100 \%$ & 2079295 & $100 \%$ & -- \\
\hline
\end{tabular}

Secondary Assembly. As shown in Table 3, there are 12 auto recalls caused by braking system defects attributable to ASR/ESP secondary assembly, taking $11.54 \%$ of total recall times; there are 10 auto recalls caused by braking system defects attributable to pneumatic service brake secondary assembly, taking $9.62 \%$ of total recall times; there are 66 recalls caused by such defects attributable to pneumatic service brake secondary assembly, taking $63.46 \%$; there are 16 recalls caused by such defects attributable to parking brake secondary assembly, taking $15.38 \%$ of total recall times.

Tab. 3 Recall Times and Percentage Caused by Secondary Assemblies Involved in Braking System Defects

\begin{tabular}{ccccc}
\hline Secondary Assembly & Recall Times & $\begin{array}{c}\text { Percentage of } \\
\text { Total Times }\end{array}$ & Recalled Quantity & $\begin{array}{c}\text { Percentage of } \\
\text { Total Vehicles }\end{array}$ \\
\hline ASR/ESP & 12 & $11.54 \%$ & 246756 & $11.87 \%$ \\
Pneumatic service brake & 10 & $9.62 \%$ & 354523 & $17.05 \%$ \\
Hydraulic service brake & 66 & $63.46 \%$ & 1376344 & $66.19 \%$ \\
Parking brake & 16 & $15.38 \%$ & 101672 & $4.89 \%$ \\
Total & 104 & $100 \%$ & 2079295 & $100 \%$ \\
\hline
\end{tabular}

Enterprise Type. As shown in Table 4, there are 51 domestic auto recalls, taking $49.04 \%$ of total recall times and 1,585,233 vehicles are involved, taking $76.24 \%$ of total recalled vehicles. There are 53 imported vehicle recalls, taking 50.96\% of total recall times, and 494,062 vechiles are involved, taking $23.76 \%$ of total recalled vehicles.

Tab. 4 Enterprise Type Involving in Auto Recalls Caused by Braking System Defects

\begin{tabular}{ccccc}
\hline Domestic/Import & Recall Times & $\begin{array}{c}\text { Percentage of Total } \\
\text { Times }\end{array}$ & Recalled Quantity & $\begin{array}{c}\text { Percentage of } \\
\text { Total Vehicles }\end{array}$ \\
\hline Domestic & 51 & $49.04 \%$ & 1585233 & $76.24 \%$ \\
Import & 53 & $50.96 \%$ & 494062 & $23.76 \%$ \\
Total & 104 & $100 \%$ & 2079295 & $100 \%$ \\
\hline
\end{tabular}

Vehicle Type. As shown in Table 5, there are 88 domestic vehicle recalls involving passenger cars among 104 recalls caused by braking system defects, taking $84.62 \%$ of total recall times. There are 9 auto recalls involving freight cars, taking $8.65 \%$ of total recall times. There are 7 recalls involving coaches, taking $6.73 \%$ of total recall times. 
Tab. 5 Vehicle Types Involved in Auto Product Recalls Caused by Braking System Defects

\begin{tabular}{ccccc}
\hline Vehicle Type & Recall Times & $\begin{array}{c}\text { Percentage of } \\
\text { Total Times }\end{array}$ & Recalled Quantity & $\begin{array}{c}\text { Percentage of } \\
\text { Total Vehicles }\end{array}$ \\
\hline Passenger car & 88 & $84.62 \%$ & 2075701 & $99.83 \%$ \\
Freight car & 9 & $8.65 \%$ & 452 & $0.02 \%$ \\
Coach & 7 & $6.73 \%$ & 3142 & $0.15 \%$ \\
Total & 104 & $100 \%$ & 2079295 & $100 \%$ \\
\hline
\end{tabular}

Brand Attribute. This study divides brand attributes of auto products into three types, respectively of independent, joint venture and import in order to analyze brand attributes involved in auto recalls caused by braking system. The independent brand refers to the brand that is self-developed by domestic enterprises and has proprietary intellectual property rights. The joint brand is also called joint venture independent brand, and refers to the brand that domestic enterprises buy, introduce foreign product technical platforms and based on this, develops their own proprietary intellectual property rights. The import brand refers to the brand whose products and relevant intellectual property rights all belong to foreign enterprise.

Tab. 6 Brand Attributes Involved in Auto Recalls Caused by Braking System

\begin{tabular}{ccccc}
\hline $\begin{array}{c}\text { Joint venture/ } \\
\text { independent/imported }\end{array}$ & Recall Times & $\begin{array}{c}\text { Percentage of } \\
\text { Total Times }\end{array}$ & Recalled Quantity & $\begin{array}{c}\text { Percentage of } \\
\text { Total Vehicles }\end{array}$ \\
\hline Independent & 23 & $22.12 \%$ & 248744 & $11.96 \%$ \\
Joint venture & 28 & $26.92 \%$ & 1336489 & $64.28 \%$ \\
Import & 53 & $50.96 \%$ & 494062 & $23.76 \%$ \\
Total & 104 & $100 \%$ & 2079295 & $100 \%$ \\
\hline
\end{tabular}

As shown in Table 5, there are 23 auto recalls involving independent brands, taking $22.12 \%$ of total recall times; 248,744 vehicles are involved, taking $11.96 \%$ of total recalled vehicles; there are 28 auto recalls involving joint venture brands, taking $26.92 \%$ of total recall times; $1,336,489$ vehicles are involved, taking $64.28 \%$ of total recalled vehicles; there are 53 auto recalls involving independent brands, taking $50.96 \%$ of total recall times; 494,062 vehicles are involved, taking $23.76 \%$ of total recalled vehicles.

\section{Conclusion}

The performance of auto braking system has a direct impact on travelling safety and it is an important goal for auto enterprises to guarantee and improve the safety of auto braking system. The features analysis of auto recalls caused by braking system defects in China during 2004-2015 shows that, the braking system defects attributable to hydraulic service brake secondary assembly take the highest proportion among all auto recalls caused by braking system defects in China; main vehicles involved are passenger cars and main auto brands involved are joint-venture brands; the recall times involving domestic vehicles and imported vehicles is about the same, but the quantity of domestic vehicles involving recalls is 3.3 times that of imported vehicles. In addition, statistical analysis results also show that although the recall times influenced by DPAC are small, a wider range of influence is produced. This indicates that China's auto recall competent department plays an important role in promoting the improvement of auto braking system defects. 


\section{Acknowledgement}

This work was financially supported by the Fundamental Research Funds of China National Institute of Standardization titled Research on Early Warning Model of Consumption Based on Risk Assessment of Defective Products (No. 282016Y-4701).

\section{References}

[1]Wei Wei, Xia Chen: Intelligence, 35(2012) (In Chinese)

[2]Chen Wang, Lisheng He: Journal of Wuhan University of Technology, Information \& Management Engineering, 23(2001) (In Chinese)

[3]Yuanfang Zhang: Western China Communication Science \& Technology, 8(2011) (In Chinese)

[4]Yuzhong Chen, Chen Liu, Jinhuan Zhang: Journal of Automotive Safety and Energy, 6(2015) (In Chinese) 